\title{
Suspecting dementia: canaries, chameleons and zebras
}

\author{
Jeremy C S Johnson (D) , ${ }^{1}$ Laura McWhirter, ${ }^{2}$ Chris J D Hardy, ${ }^{1}$ \\ Sebastian J Crutch, ${ }^{1}$ Charles R Marshall, ${ }^{3,4}$ Catherine J Mummery, ${ }^{1}$ \\ Jonathan D Rohrer, ${ }_{1}^{1}$ Martin N Rossor, ${ }^{1}$ Jonathan M Schott, ${ }^{1}$ \\ Rimona S Weil (D) , ${ }^{1}$ Nick C Fox, ${ }^{1}$ Jason D Warren ${ }^{1}$
}

'Dementia Research Centre, UCL, London, UK ${ }^{2}$ Centre for Clinical Brain Sciences, University of Edinburgh, Edinburgh, UK ${ }^{3}$ Preventive Neurology Unit, Wolfson Institute of Preventive Medicine, London, UK ${ }^{4}$ Department of Neurology, Royal London Hospital, London, UK

\section{Correspondence to} Prof Jason D Warren, Dementia Research Centre, University College London, London WC1N 3BG, UK; jason.warren@ucl. ac.uk

Accepted 20 April 2021 Published Online First 1 July 2021

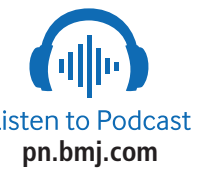

Check for updates

(c) Author(s) (or their employer(s)) 2021. No commercial re-use. See rights and permissions. Published by BMJ.

To cite: Johnson JCS, McWhirter L, Hardy CJD, et al. Pract Neurol 2021;21:300312.

\begin{abstract}
The early and accurate diagnosis of dementia is more important than ever before but remains challenging. Dementia is increasingly the business of neurologists and, with ageing populations worldwide, will become even more so in future. Here we outline a practical, symptom-led, bedside approach to suspecting dementia and its likely diagnosis, inspired by clinical experience and based on recognition of characteristic syndromic patterns. We show how clinical intuition reflects underlying signature profiles of brain involvement by the diseases that cause dementia and suggest next steps that can be taken to define the diagnosis. We propose 'canaries' that provide an early warning signal of emerging dementia and highlight the 'chameleons' that disguise or mimic this, as well as the 'zebras' that herald a rare (and sometimes curable) diagnostic opportunity.
\end{abstract}

\section{INTRODUCTION}

As the number of people worldwide with dementia approaches 50 million, the need for early and accurate diagnosis is more urgent than ever. ${ }^{1}$ Timely diagnosis avoids the limbo of diagnostic uncertainty and futile cycles of investigation, equips patients and families to engage appropriate support and to plan for the future, and directs rational and appropriate management. ${ }^{2}$ It will also be essential for the effective deployment of disease-modifying therapies that are on the horizon. However, the early diagnosis of dementia is challenging and remains peculiarly reliant on clinical judgement (box 1); the target diseases are complex and affect aspects of higher brain function that are generally not assessed in routine neurological practice. Treatises on dementia conventionally list the clinical features of particular diseases - in the trenches, however, the biggest challenge is often suspecting dementia in the first place and deciding why this is not 'just' Alzheimer's disease.

Dementia is a syndrome that can be defined very generally as a progressive decline in cognitive function and/or behaviour that impacts daily life functioning. As such, it has a multiplicity of causes. Most of these are neurodegenerative pathologies that are not presently reversible; however, the rare exceptions are not to be missed. A key theme in dementia (especially in neurodegenerative disease) is that the causative pathologies initially target certain brain functions relatively selectively, due to a predilection of pathogenic proteins to involve particular brain networks. ${ }^{3}$ Over time, these signature patterns become obscured as the spread of pathological change leads to convergent, widespread damage and impairment. The window of greatest opportunity for accurate diagnosis (and anticipated interventions) is therefore early-stage disease. Appreciating how profiles of brain damage relate to cognitive deficits is key to deciding which diseases are likely in patients presenting with suspected dementia.

Here we outline a symptom-led, bedside approach to suspecting dementia that we have found useful in busy neurological clinics. First, we consider clues that help one decide whether or not cognitive decline is present and, if so, the likely cause. We show how these clues predictably reflect underlying signature patterns of brain involvement by causative pathologies and suggest next steps that can be taken to define the diagnosis. As with many other disorders, the neurologist's essential task is to identify 'canaries' that provide an early warning signal of emerging disease, avoid being misled by 'chameleons' that disguise or mimic this and remain alert to the occasional 'zebra' that heralds a rare (and sometimes curable) diagnosis.

We suggest some general principles and tools for cognitive assessment in box 1 and 
Box 1 Some principles of bedside cognitive assessment

History taking

- History is the most important aspect of successful dementia diagnosis.

- Obtaining a history from reliable informants who know the patient well is integral and interviewing them separately may encourage sharing of sensitive or embarrassing clues to the diagnosis.

- A minute or two spent putting the patient and family at ease is well invested.

- How organised and detailed patients seem when describing their symptoms is informative, particularly if at odds with performance on formal cognitive tests.

- Interpretation of cognitive or behavioural changes depends on an appreciation of the patient's sociocultural background, education, occupation, premorbid language skills, any pre-existing specific developmental or other deficits, and medical and psychiatric history (including medications).

- Cognitive concerns will most frequently be framed as a non-specific 'memory' problem: this is the most ubiquitous of several potential 'pitfall' symptoms that must be deconstructed (see table 2).

- Domains of cognitive function and behaviour that may not be volunteered should also be explored (as these help define the cognitive profile), framing these as questions about functioning in daily life.

- Particularly in younger people, a detailed family history is essential (including parents' diagnoses and age at death if relevant, and the ages of any siblings).

\section{Examination}

- It is first essential to establish that the patient is alert and cooperative and that their peripheral vision and hearing are adequate (or corrected as appropriate).

- Observing the patient's conduct and interaction with the examiner and others is often telling (it may point to frontal lobe dysfunction more clearly than any test; see table 2).

- To corroborate the history and to build a diagnostic profile of cognitive deficits, it is helpful to have a scheme for testing cognition (a 'walk around the brain', table 1), armed with some tools to elicit cognitive deficits (figure 1): the cognitive profile in turn predicts the underlying pattern of brain involvement (figure 2).

- Quantitative cognitive assessments such as the MiniMental State Examination, the Montreal Cognitive Assessment and Addenbrooke's Cognitive Examination are widely available; however, each has its limitations ${ }^{1}$ ${ }^{33}$ and none in itself should be used to diagnose or exclude dementia.

- The general neurological and systemic examinations are essential, particularly for substantiating diagnoses other than Alzheimer's disease (see tables 3 and 4). figure 1 and outline a bedside framework for cognitive history taking and examination in table 1. Diagnostic canaries based on characteristic patterns of cerebral involvement are listed in table 1; potential pitfalls are listed in table 2, chameleons in table 3 and zebras in table 4.

\section{DOES THIS PATIENT HAVE DEMENTIA?}

Distinguishing early dementia from the 'worried well' or a 'functional' cognitive disorder is an increasingly frequent challenge faced by neurologists as public awareness and anxiety about dementia continue to increase. ${ }^{4} \mathrm{~A}$ functional cognitive disorder should be considered if there are positive features of internal inconsistency, that is, ability to perform a task well at certain times, but with significant difficulty when it becomes the focus of attention. The person who gives a detailed (or even overinclusive) account of their memory lapses, attributes their difficulties eloquently to specific past events and who is substantially more concerned about their cognitive function than their partner, children or colleagues-often attending clinic unaccompanied-is more likely to be anxious or to have a functional cognitive disorder than dementia. People with obsessional personalities are more prone to overinterpret the imperfections of normal memory. There is often a flavour of wavering concentration, such as being unable to remember why one has entered a room, misplacing household items in odd locations (eg, keys in the fridge) or 'going blank' during a conversation only to have the required information re-emerge soon afterward. Cognitive testing frequently generates considerable anxiety, inducing 'thought-blocking' and performance may vary widely between assessments, often leading to marked inconsistencies (disastrous test scores despite evident competence in daily life). This contrasts with the 'face-saving', humour and minimisation often seen in Alzheimer's disease, or indifference in diseases where insight is impaired. However, particularly in older patients, functional cognitive impairment may signal an emerging neurodegenerative process which declares itself subsequently.

Depression or other primary psychiatric diagnoses must not be overlooked-these are potentially treatable and undetected carry significant risk of harm. There is often a history of previous psychiatric episodes, though this may not be volunteered. Core depressive symptoms are low mood or anhedonia, variably accompanied by fatigue, psychomotor retardation, impaired concentration, a sense of personal worthlessness, significant change in appetite or recurrent morbid thoughts. ${ }^{5}$ Depressed patients are often downcast and disengaged, giving frequent 'don't know' responses. Active psychosis also leads to poor engagement, and there may be evidence of delusional thinking or verbal hallucinations. It is important to keep in mind that anxiety, mood changes and psychosis occur not uncommonly in 'organic' dementias and may be early features ${ }^{67}$; moreover, organic deficits may be elaborated by patients with abnormal illness behaviour, and certain syndromes (such as parietal presentations of Alzheimer's 
A

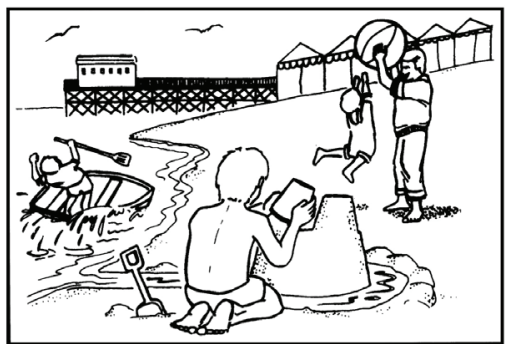

C

John Gifford was the kind of person who would go off sailing in his yacht the 'Neva' around the island of Scorba whenever there were signs of chaos at work. He had a thorough knowledge of this area as he had grown up there in his childhood, and this was how he always sought relaxation from the busy routine of the office life at Bergess, Challice \& $\mathrm{C} 0$. He would sit on deck sipping his champagne, as the breeze tangled his normally immaculately combed hair. Gradually his business worries would recede. Dressed in his old, baggy sweater, decrepit suede boots and with his stubbly beard he felt quite the part of an ancient mariner.
B
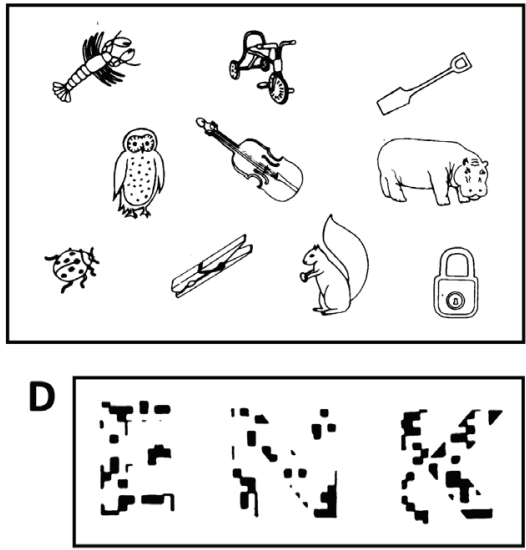

E

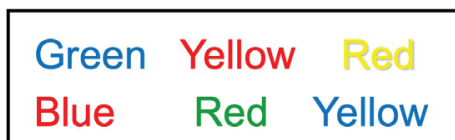

Figure 1 Examples of aids for testing cognition at the bedside. These are some examples of materials that we use to sample a range of cognitive domains (see also table 1 and figure 2) when examining a patient with suspected dementia (shown with permission of Professor E K Warrington). (A) A pictorial scene for description, to assess connected language (fluency, word finding and expressive grammar) and ability to parse a complex environment (visuospatial processing). (B) An array of pictures of familiar items for assessing word retrieval (naming), single-word comprehension (pointing to an item named by the examiner) and subsequent item recall (anterograde episodic memory). (C) A passage for reading aloud to elicit difficulties sounding non-words (personal names, eg, 'Scorba'; phonological dyslexia) or irregular words (eg, 'yacht', regularised as 'yached'; surface dyslexia) or with tracking lines of text (visuospatial processing). (D) Fragmented letters to assess visual apperceptive function. (E) A Stroop task, requiring the patient to state the (conflicting) colour of the ink in which each colour name is printed (in fluent readers of English, a test of response inhibition-one aspect of executive function).

disease and behavioural variant frontotemporal dementia) are notoriously prone to psychiatric mislabelling even by experienced clinicians.

\section{SOME IMPORTANT CANARIES}

\section{Alzheimer's disease}

Older patients with episodic and topographical memory impairment that declines over time will most commonly have emerging Alzheimer's disease. Details of important events and conversations are not retained, questions become repetitive and there is often a loss of facility with route-finding and a history of becoming lost. There may be a signal 'catastrophic' episode (often, disorientation in unfamiliar surroundings, e.g. while on holiday) preceding more pervasive deterioration. Difficulty following conversations in background noise and dislike of noisy environments (due to impaired auditory scene processing) tend to develop early. ${ }^{8}$ Loss of pleasure in reading (probably multifactorial in nature) is also frequently reported. Retained (partial) awareness of limitations as well as endogenous emotional changes wrought by the disease often lead to loss of confidence or initiative, embarrassment, anxiety and withdrawal from social activities, manifesting in the clinic as a tendency to 'trail' the accompanying person into the room and to turn to them ('head-turning sign') when asked a question. ${ }^{69}$ On bedside testing, the extent to which cognitive impairment has been masked by a well-preserved social façade may be surprising: knowledge of current affairs tends to be vague, recall of previously presented items does not benefit from cueing and topographical material (such as reconstructing the journey to the hospital) may be notably affected.

Beyond memory, parietal cortical functions including word retrieval, praxis, calculation and visuospatial function are affected relatively early in Alzheimer's disease. There may be difficulties with word finding, handling household appliances, managing money or visuospatially demanding activities such as driving or do-it-yourself. Coming to grips with new technology taxes learning, executive and parietal functions and is often particularly challenging.

\section{Dementia with Lewy bodies}

Dementia commonly develops in Parkinson's disease (particularly in older patients) and is a core feature of Lewy body pathology. ${ }^{10}$ Clues include an early predisposition to severe, prolonged delirium (for example, attending a minor infection or surgical procedure) and sometimes acting out of dream content (REM sleep behaviour disorder, due to loss of normal skeletal muscle atonia). Later, misperceptions and hallucinations (usually predominantly visual) develop, though these may not be volunteered. Initially, they may be brief transients glimpsed in the periphery but evolve into vivid, animate entities (commonly faces, people or animals) that emerge out of background features (such as foliage or a pile of clothes) in stereotyped fashion, particularly under low-light conditions. In contrast to psychotic or dopamine-driven hallucinations, these are typically non-threatening though insight into their nature may be impaired. An 'extracampine' 
Table 1 Bedside assessment of the patient with suspected dementia: a 'walk around the cognitive brain'

\begin{tabular}{|c|c|c|c|c|c|}
\hline Cognitive domain & $\begin{array}{l}\text { Leading or early } \\
\text { symptoms }\end{array}$ & Associated symptoms & Examination findings & Brain region(s) & First thoughts \\
\hline \multirow[t]{2}{*}{$\begin{array}{l}\text { Behaviour (social and } \\
\text { emotional) }\end{array}$} & $\begin{array}{l}\text { Loss of empathy/ } \\
\text { emotional awareness } \\
\text { (eg, family events such } \\
\text { as funerals, illnesses and } \\
\text { warmth toward children/ } \\
\text { pets) and self-centredness }\end{array}$ & $\begin{array}{l}\text { Disinhibition, loss of initiative, } \\
\text { obsessionality/rituals (eg, clock } \\
\text { watching), gluttony/sweet } \\
\text { tooth/food faddism, altered } \\
\text { interests/humour, loss of insight/ } \\
\text { anosognosia }\end{array}$ & $\begin{array}{l}\text { Impulsive, inert, disinhibited } \\
\text { interaction, '1000-yard stare' }\end{array}$ & $\begin{array}{l}\text { Frontal lobe (especially } \\
\text { right), right temporal lobe, } \\
\text { other }\end{array}$ & $\begin{array}{l}\text { Behavioural variant } \\
\text { frontotemporal } \\
\text { dementia }\end{array}$ \\
\hline & $\begin{array}{l}\text { Irritability, more anxious } \\
\text { and 'clingy' }\end{array}$ & Quieter in social situations & Diffident/head turning & & Alzheimer's disease ${ }^{*}$ \\
\hline $\begin{array}{l}\text { Language output } \\
\text { (speech sounds, } \\
\text { sentences and prosody) }\end{array}$ & $\begin{array}{l}\text { Stumbling over words, } \\
\text { especially public speaking }\end{array}$ & $\begin{array}{l}\text { Mixing up 'yes'/no', } \\
\text { mispronunciations, monotonous/ } \\
\text { odd accent, } \\
\text { grammatical/spelling slips }\end{array}$ & $\begin{array}{l}\text { Effortful speech, reduced } \\
\text { articulatory agility (repeating } \\
\text { syllable strings, eg, 'puh-kuh- } \\
\text { tuh'), impaired repeating single } \\
\text { words and following complex } \\
\text { commands }\end{array}$ & $\begin{array}{l}\text { Left inferior frontal gyrus/ } \\
\text { peri-Sylviant }\end{array}$ & $\begin{array}{l}\text { Non-fluent primary } \\
\text { progressive aphasia }\end{array}$ \\
\hline
\end{tabular}

Word-finding difficulty, Reduced speech quantity, pauses Reduced picture naming losing thread of sentences

\begin{tabular}{|c|c|c|c|c|c|}
\hline \multirow[t]{2}{*}{$\begin{array}{l}\text { Knowledge of words } \\
\text { (vocabulary), objects } \\
\text { and concepts }\end{array}$} & \multirow[t]{2}{*}{$\begin{array}{l}\text { Forgetting names, } \\
\text { circumlocutions, vague } \\
\text { expressing thoughts and } \\
\text { 'going deaf' }\end{array}$} & $\begin{array}{l}\text { Asking meaning of words, } \\
\text { keeping personal 'dictionaries' } \\
\text { and decline in spelling/ } \\
\text { understanding written words }\end{array}$ & $\begin{array}{l}\text { Reduced knowledge of specialist } \\
\text { vocabulary, } \neq \text { reduced naming } \\
\text { of objects/ability to identify } \\
\text { pictures/define words named } \\
\text { by examiner, surface dyslexia } \\
\text { (irregular words, eg, 'yacht') }\end{array}$ & \multirow[t]{2}{*}{$\begin{array}{l}\text { Left anteroinferior } \\
\text { temporal lobe }\end{array}$} & \multirow[t]{2}{*}{$\begin{array}{l}\text { Semantic primary } \\
\text { progressive aphasia }\end{array}$} \\
\hline & & $\begin{array}{l}\text { Difficulty choosing groceries/ } \\
\text { tools, etc } \S\end{array}$ & $\begin{array}{l}\text { Unable to describe/demonstrate } \\
\text { use of an object§ (visual } \\
\text { agnosia) }\end{array}$ & & \\
\hline $\begin{array}{l}\text { Reading, spelling and } \\
\text { calculation }\end{array}$ & $\begin{array}{l}\text { Loss of pleasure reading } \\
\text { Less numerical facility (eg, } \\
\text { change) }\end{array}$ & $\begin{array}{l}\text { Losing place reading text, } \\
\text { difficulty resolving closely spaced } \\
\text { text and decline in spelling ability }\end{array}$ & $\begin{array}{l}\text { Difficulty reading blocked text } \\
\text { and acalculia on simple mental } \\
\text { arithmetic }\end{array}$ & Left parietal lobe & $\begin{array}{l}\text { Posterior cortical } \\
\text { atrophy, logopenic } \\
\text { aphasia and Alzheimer's } \\
\text { disease }\end{array}$ \\
\hline $\begin{array}{l}\text { Working memory } \\
\text { (verbal) }\end{array}$ & Poor 'concentration' & $\begin{array}{l}\text { Difficulty holding information for } \\
\text { example, a new phone number } \\
\text { in mind } \\
\text { Losing thread of conversation }\end{array}$ & $\begin{array}{l}\text { Reduced forward (passive) digit } \\
\text { span, reduced reverse (active) } \\
\text { digit span and reduced repetition } \\
\text { of phrases more than words }\end{array}$ & $\begin{array}{l}\text { Left temporoparietal } \\
\text { junction/frontal lobe }\end{array}$ & $\begin{array}{l}\text { Logopenic aphasia and } \\
\text { Alzheimer's disease }\end{array}$ \\
\hline \multirow[t]{3}{*}{$\begin{array}{l}\text { Action (learnt/ } \\
\text { voluntary: praxis) }\end{array}$} & \multirow[t]{2}{*}{$\begin{array}{l}\text { Difficulty learning new } \\
\text { devices, loss of facility } \\
\text { with do-it-yourself, etc }\end{array}$} & $\begin{array}{l}\text { Difficulty using household } \\
\text { gadgets }\end{array}$ & $\begin{array}{l}\text { Ideomotor limb apraxia: impaired } \\
\text { copying meaningless/sequential } \\
\text { gestures (Luria), ideational limb } \\
\text { apraxia: impaired pantomime of } \\
\text { learnt actions (eg, tool, waving) }\end{array}$ & \multirow[t]{2}{*}{ Left parietal lobe } & \multirow[t]{2}{*}{$\begin{array}{l}\text { Posterior cortical } \\
\text { atrophy and } \\
\text { corticobasal syndrome }\end{array}$} \\
\hline & & Difficulty positioning self in space & $\begin{array}{l}\text { Bottom apraxia (difficulty sitting } \\
\text { on chair) }\end{array}$ & & \\
\hline & $\begin{array}{l}\text { Loss of facility whistling/ } \\
\text { singing }\end{array}$ & Difficulty swallowing & $\begin{array}{l}\text { Orofacial apraxia: volitional } \\
\text { cough/yawn/blow kiss, etc }\end{array}$ & Left frontal lobet & $\begin{array}{l}\text { Non-fluent primary } \\
\text { progressive aphasia }\end{array}$ \\
\hline Object analysis (visual) & $\begin{array}{l}\text { Difficulty reading large/ } \\
\text { unusual (eg, pixelated/ } \\
\text { CAPTCHA) font; } \\
\text { not confident on } \\
\text { escalators; } \\
\text { often multiple optician } \\
\text { visits }\end{array}$ & $\begin{array}{l}\text { Difficulty interpreting complex } \\
\text { scenes with patterns, overlaid } \\
\text { objects, identifying slopes/ } \\
\text { steps, etc; } \\
\text { difficulty recognising or } \\
\text { misrecognising objects in } \\
\text { suboptimal viewing conditions }\end{array}$ & $\begin{array}{l}\text { Difficulty perceiving fragmented } \\
\text { letters/pictures, distorted views }\end{array}$ & Right parietal lobe & $\begin{array}{l}\text { Posterior cortical } \\
\text { atrophy and dementia } \\
\text { with Lewy bodies }\end{array}$ \\
\hline \multirow[t]{4}{*}{$\begin{array}{l}\text { Perception } \\
\text { (early sensory-visual, } \\
\text { auditory, somatic and } \\
\text { interoceptive) }\end{array}$} & $\begin{array}{l}\text { Difficulty driving if night- } \\
\text { time/raining }\end{array}$ & $\begin{array}{l}\text { Abnormally prolonged after- } \\
\text { images (colour 'washes', often } \\
\text { red/green), visual 'tilt' and other } \\
\text { distortions }\end{array}$ & $\begin{array}{l}\text { Impaired colour/shape } \\
\text { discrimination (e.g., oblong vs } \\
\text { square) }\end{array}$ & \multirow[t]{4}{*}{$\begin{array}{l}\text { Sensory cortices/ } \\
\text { thalamus } 9\end{array}$} & $\begin{array}{l}\text { Posterior cortical } \\
\text { atrophy, 'visual' } \\
\text { Creutzfeldt-Jakob } \\
\text { disease }\end{array}$ \\
\hline & $\begin{array}{l}\text { 'Double vision', brief } \\
\text { misperceptions }\end{array}$ & Illusions/hallucinations & Check visual acuity & & $\begin{array}{l}\text { Dementia with Lewy } \\
\text { bodies }\end{array}$ \\
\hline & $\begin{array}{l}\text { Dislikes noisy } \\
\text { environments }\end{array}$ & Difficulty conversing in noise & Check peripheral hearing & & $\begin{array}{l}\text { Alzheimer's disease and } \\
\text { variants }\end{array}$ \\
\hline & Tinnitus/hyperacusis & $\begin{array}{l}\text { Altered pain/temperature } \\
\text { awareness }\end{array}$ & Check basic sensory function & & $\begin{array}{l}\text { Semantic primary } \\
\text { progressive aphasia } \\
\text { and behavioural } \\
\text { variant frontotemporal } \\
\text { dementia }\end{array}$ \\
\hline
\end{tabular}

Left temporoparietal Logopenic aphasia junction 
Table 1 Continued

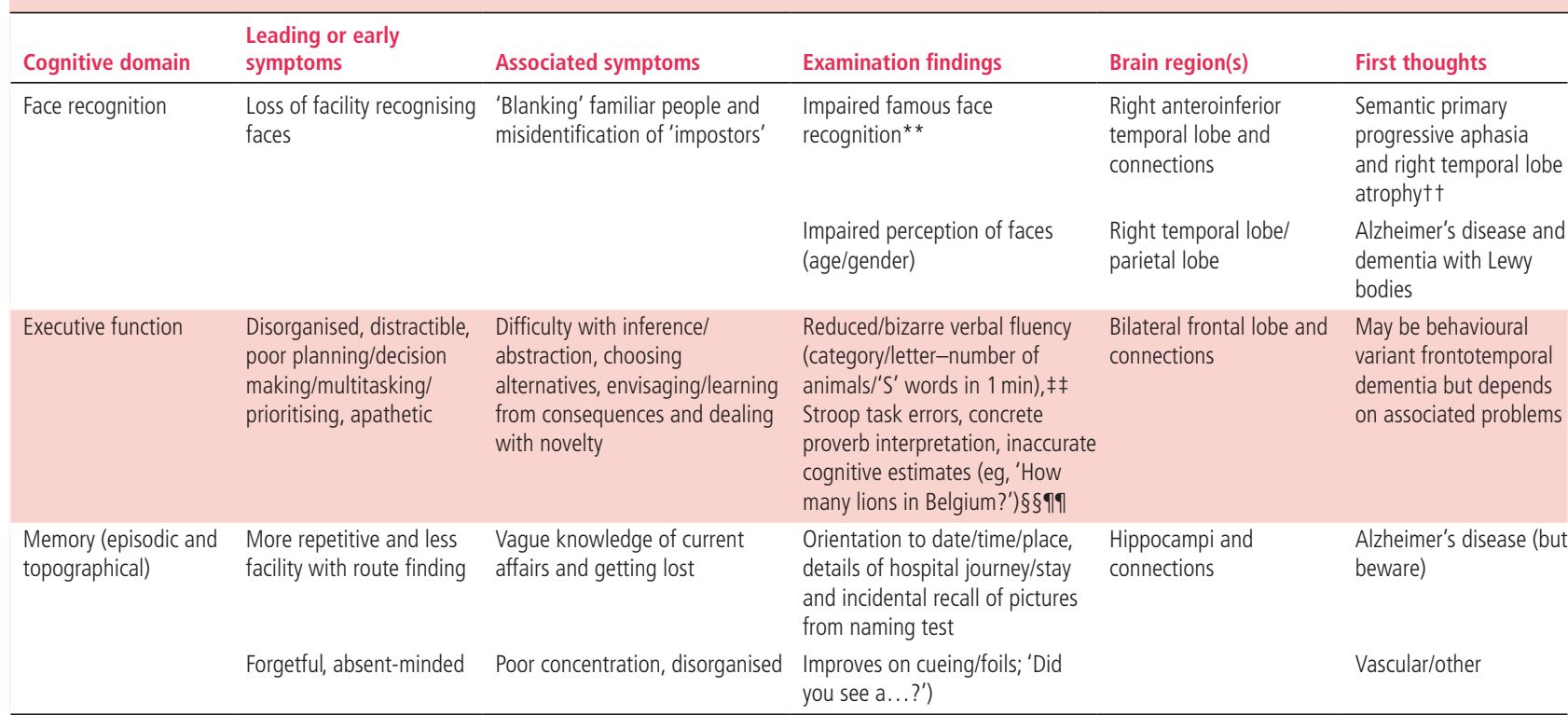

This table presents early symptoms ('canaries'; see also table 2) that signal difficulty in each major cognitive domain, together with associated symptoms that may be elicited on history. For each domain, we suggest bedside tests (see also box 1) and features that may be used to corroborate the historical impression and indicate major neuroanatomical associations (see also figure 2) and leading diagnostic considerations.

*Refers to the clinical syndrome of typical (memory-led) Alzheimer's disease.

†Prosody/ singing may be additionally linked to right peri-Sylvian cortical regions

\#Initial loss of knowledge of lower-frequency words reflecting patient's interests/occupation.

$\S$ May indicate visual agnosia (the patient with apraxia recognises how an object is used).

IUsually conjoint 'top-down' abnormalities in attentional/executive/semantic functions.

**Ask for other biographical details if patient cannot name.

†tRefers to the syndrome associated with right temporal lobe atrophy, within the behavioural variant frontotemporal dementia spectrum.

‡łIn non-aphasic patients.

$\S \S$ Dependent on education and culture.

११The manner in which the patient approaches executive tests is also informative, for example, are they impulsive? do they produce odd items on fluency tasks? do they produce overprecise, incorrect estimates that they cannot revise? etc.

sense of a presence beyond the field of vision is common. Marked fluctuations in alertness, attention and cognitive competence even within the course of a day (particularly deterioration later in the day) are also characteristic. ${ }^{11}$ Complaints of 'double vision' and problems reading (without identifiable ocular pathology) are common, and difficulty using gadgets such as a smartphone exposes executive and parietal dysfunction. Features of associated Parkinsonism (such as hypomimia or gait changes) may be subtle initially but it is worth asking about autonomic symptoms (particularly urinary urgency, nocturia or unexplained collapses). ${ }^{12} 13$

\section{Vascular cognitive impairment}

The most common cognitive syndrome of cerebrovascular disease is not the stepwise decline in function of classical teaching, but an insidious deterioration characterised by disorganisation, loss of verve and initiative, irritability, mental rigidity, emotional lability and other mood changes, and sometimes inappropriate or disinhibited social behaviour. Vascular risk factors are common, but their absence does not exclude the diagnosis. Examination typically reveals cognitive and affective blunting, executive dysfunction, impaired attention and recall (which in contrast to Alzheimer's disease, does generally benefit from cueing) with variable additional, more focal deficits; ${ }^{14} 15$ however these may be over-estimated due to often significant slowing of mentation. Brisk tendon and pout reflexes (despite flexor plantar responses) where present are characteristic and in more advanced cases gait may be wide-based and shuffling. Dysphagia may develop later in the disease. Though this is one of the few diagnoses in neurology where a compatible scan is sine qua non, over-diagnosis of incidental vascular changes is a significant pitfall, compounded by the frequent coexistence of cerebrovascular with primary neurodegenerative pathologies.

\section{SOME CHAMELEONS AND ZEBRAS Alzheimer's disease variants}

Atypical presentations of Alzheimer's disease dominated by non-amnestic deficits are not uncommon, particularly in younger people ${ }^{1617}$; conversely, Alzheimer's disease is simulated by a variety of other disease processes. ${ }^{18}$ Table 3 summarises some of these chameleons; it is particularly important to consider potentially reversible mimics, such as transient epileptic amnesia or obstructive sleep apnoea. ${ }^{18-24}$ There are three major Alzheimer variant syndromes, likely reflecting differential involvement of the same core temporo-parieto-frontal brain network targeted by Alzheimer pathology (see tables 1 and 2, and figure 2). ${ }^{16-18}$ These variants lie on a clinical continuum and overlap is frequent. 
How to do it

Table 2 Some noteworthy potential 'pitfall' symptoms and signs requiring further clarification or interpretation in suspected dementia

\begin{tabular}{|c|c|c|}
\hline Feature & Clarification/interpretation & Major causes \\
\hline \multicolumn{3}{|c|}{ Ambiguous symptoms } \\
\hline 'Poor memory' & $\begin{array}{l}\text { Often used as a shorthand for 'cognitive problem'; does it mean episodic } \\
\text { memory (events, routes, conversations, etc), semantic memory (words } \\
\text { and concepts) or another domain of cognition? If the issue is with } \\
\text { memory, is it with encoding information (attention), retaining new } \\
\text { information (anterograde memory) or retrieving old information? }\end{array}$ & $\begin{array}{l}\text { Any (may have poor episodic memory } \\
\text { in dementia with Lewy bodies, } \\
\text { frontotemporal dementia, etc, as well as } \\
\text { Alzheimer's disease }^{*} \text { ) }\end{array}$ \\
\hline
\end{tabular}

$\begin{array}{ll}\text { 'Getting lost' } & \text { Is this truly difficulty completing a route without assistance } \\ \text { (topographical disorientation) or wandering (but ultimately getting } \\ \text { there)? A useful question can be 'how would you make your way home } \\ \text { from here if you had to do it alone'? }\end{array}$

$\begin{array}{ll}\text { 'Lost interest in reading' } & \begin{array}{l}\text { Is this a general loss of concentration or initiative, anhedonia, difficulty } \\ \text { following the plot or a more specific problem tracking lines of text? }\end{array} \\ \text { 'Doesn't recognise people' } & \begin{array}{l}\text { Is this inability to recall their name (personal anomia, common) } \\ \text { or to recognise faces or voices, 'blanking' familiar people? (true } \\ \text { prosopagnosia or phonagnosia, uncommon) }\end{array} \\ \text { 'More anxious/irritable' } \quad \begin{array}{l}\text { Might be psychiatric (eg, atypical depression) but also an early feature } \\ \text { of many 'organic' dementias }\end{array}\end{array}$

'Black sheep of family' Youthful delinquency that contrasts with law-abiding siblings

Counterintuitive symptoms

'Asks meaning of words' Loss of ability to understand words in a familiar language

Alzheimer's disease (topography) and behavioural variant frontotemporal dementia (wandering)

Alzheimer's disease/others (retrieval), semantic primary progressive aphasia (vocabulary) and non-fluent primary progressive aphasia (articulation)

Alzheimer's disease (multifactorial) and posterior cortical atrophy (text tracking)

Alzheimer's/others (names), semantic primary progressive aphasia/right temporal lobe atrophy† (familiarity)

Alzheimer's disease, dementia with Lewy bodies, vascular and some frontotemporal dementias (eg, C9orf72 mutations)

'Reads fine print but not the headlines'

Visual apperceptive agnosia exposed by non-canonical (eg, very large or Posterior cortical atrophy pixelated) text

'Can play tennis (etc) but Static visual localisation more impaired than motion vision (or can't find ball on ground' occasionally the reverse), reflecting separable neuroanatomical Latent learning disability, very rarely genetic prion disease

'Become very musical/ Enhanced (sometimes loss of) interest/ability in abstract pursuits, religious/punctual/good at usually with loss of interest/affection for other people, on a spectrum of Sudoku'
'Says spouse is impostor' Misidentification delusion (Capgras, etc), can also be for location (eg, asks to go 'home' in own house)

'Much nastier/nicer now' Altered interpersonal awareness and conduct

Potentially misleading symptoms

'It all started after that... (accident/operation, etc)'

sually, this is attribution bias; occasionally we have seen cases where severe psychological trauma did seem to provoke catastrophic cognitive decline in a previously asymptomatic person

'Distant memories are fine' Usually they are not, but highly overlearnt or emotional memories tend to become the focus of cherished anecdote

'Poor short-term memory' To a neuropsychologist, this refers to the immediate span of working memory (up to $\sim 30 \mathrm{~s}$ ) but used colloquially to refer to recent episodic memory of variable span

'Thinks people are stealing Usually not a harbinger of psychosis but a specific delusion of theft (or from them'

'Going deaf'

'Always been spiritual'

'Unexplained aches/pains' Hypochondriasis can occasionally reflect abnormal processing of interoceptive signals such as pain
Alzheimer's disease, dementia with Lewy bodies

Behavioural variant frontotemporal dementia (nasty) and Alzheimer's disease (nice)

Behavioural variant frontotemporal

dementia and semantic primary

progressive aphasia

Any

Alzheimer's disease

Any

Alzheimer's disease, dementia with Lewy bodies

Semantic primary progressive aphasia

Dementia with Lewy bodies

Right temporal lobe atrophy and semantic primary progressive aphasia 


\begin{tabular}{|c|c|c|}
\hline Feature & Clarification/interpretation & Major causes \\
\hline \multicolumn{3}{|c|}{ Signs not to miss/misinterpret } \\
\hline Bottom apraxia & $\begin{array}{l}\text { Difficulty orienting/positioning self in space as when sitting down in a } \\
\text { chair }\end{array}$ & $\begin{array}{l}\text { Posterior cortical atrophy and } \\
\text { corticobasal syndrome }\end{array}$ \\
\hline Closing in & $\begin{array}{l}\text { Patients overlay their hand or drawing on examiner's target—feature of } \\
\text { organic apraxia }\end{array}$ & $\begin{array}{l}\text { Alzheimer's disease and posterior cortical } \\
\text { atrophy }\end{array}$ \\
\hline '(Vicar of) Dibley' sign & Binary reversals during conversation—says 'yes' but means 'no', etc & Non-fluent primary progressive aphasia \\
\hline Dysprosodia (isolated) & $\begin{array}{l}\text { Most cases of 'foreign accent syndrome' (recognisable as such, } \\
\text { sometimes simulated with pantomime exuberance) will be functional, } \\
\text { but occasionally patients present with altered prosody and linguistic } \\
\text { deficits only supervene (much) later }\end{array}$ & Non-fluent primary progressive aphasia \\
\hline Executive dysfunction & $\begin{array}{l}\text { As used, for example, in neuropsychological reports, it is not } \\
\text { synonymous with 'frontal lobe problem' but reflects processing across } \\
\text { distributed brain networks; moreover, patients with significant frontal } \\
\text { lobe dysfunction (as reflected in abnormal behaviour) may perform well } \\
\text { on executive tests }\end{array}$ & Any \\
\hline Head-turning & $\begin{array}{l}\text { To accompanying person, during history taking-lack of confidence/ } \\
\text { retained awareness of problem/poor memory }\end{array}$ & Alzheimer's disease \\
\hline Perioral dyskinesias & Subtle trembling movements of lips/lower face & Alzheimer's disease (younger onset) \\
\hline Pigeon sign & $\begin{array}{l}\text { Turns head this way and that, trying to make sense of a picture or visual } \\
\text { array }\end{array}$ & Posterior cortical atrophy \\
\hline Repetitiveness conversing & $\begin{array}{l}\text { Signifies an organic problem with anterograde episodic memory/ } \\
\text { accelerated forgetting }\end{array}$ & Alzheimer's disease \\
\hline Semantic paraphasias & $\begin{array}{l}\text { Substitution of related words on a naming task usually will not reflect } \\
\text { a primary semantic problem but more likely anomia (impaired word } \\
\text { retrieval) with attempted compensation }\end{array}$ & Alzheimer's disease, others \\
\hline Surface dyslexia & $\begin{array}{l}\text { Sounds irregularly pronounced words as they are printed, due to loss of } \\
\text { vocabulary-based reading }\end{array}$ & Semantic primary progressive aphasia \\
\hline 'Thousand yard stare' & $\begin{array}{l}\text { Sense of unease/threat conveyed by patient who lacks normal social } \\
\text { facial microreactivity }\end{array}$ & Right temporal lobe atrophy \\
\hline Tie sign & $\begin{array}{l}\text { Patient touches examiner's tie/face when trying to locate their } \\
\text { outstretched hand, due to visuospatial disorientation }\end{array}$ & Posterior cortical atrophy \\
\hline 'Variable deficit' & $\begin{array}{l}\text { Apraxia is intrinsically variable; organic cognitive impairment of any } \\
\text { cause can be impacted by stress or fatigue, and certain entities are } \\
\text { characterised by marked fluctuation } \neq \text { (sometimes sleep benefit/ } \\
\text { deterioration), due to seizures, channel dysfunction or impaired } \\
\text { dopaminergic/cholinergic switching between brain states }\end{array}$ & $\begin{array}{l}\text { Dementia with Lewy bodies (sleep } \\
\text { benefit), transient epileptic amnesia } \\
\text { (sleep deterioration), inflammatory, } \\
\text { immune }\end{array}$ \\
\hline
\end{tabular}

*Refers to the clinical syndrome of typical (memory-led) Alzheimer's disease.

tRefers to the syndrome associated with right temporal lobe atrophy, within the behavioural variant frontotemporal dementia spectrum.

$\ddagger$ Not the same as inconsistency—organic cognitive fluctuations are internally consistent.

Posterior cortical atrophy, the 'visual variant' of Alzheimer's disease, usually presents with impairments of visuospatial awareness, reading and praxis. ${ }^{17}$ Beware the patient who has made numerous futile visits to the optician or who describes more difficulty reading pixelated signs than newsprint (signifying visual apperceptive agnosia): this is the cardinal degenerative disorder of the visual brain, disrupting the interpretation of visual scenes despite normal sensory acuity. There is usually a full hand of accompanying parietal lobe deficits, but episodic memory early on is often well preserved.

Logopenic aphasia is the language-led variant of Alzheimer's disease within the primary progressive aphasia spectrum..$^{25}$ It is characterised by prominent word-finding difficulty, conversational pauses (sentences tend to trail off) with speech sound (phonological) errors and, on examination, impaired repetition of phrases despite intact repetition of single words (due to reduced verbal working memory). ${ }^{26}$

The 'frontal' (behavioural/dysexecutive) variant of Alzheimer's disease remains the least well defined. ${ }^{27}$ Clinically, it can closely resemble the behavioural variant of frontotemporal dementia, but prominent accompanying memory impairment and confabulation may be bedside clues to the diagnosis.

\section{Frontotemporal dementia syndromes}

Among the 'zebras' of dementia diagnosis, the frontotemporal dementias are particularly important because they are collectively a major cause of dementia in middle life and wreak havoc on social and occupational functioning. This is a diverse group of diseases with complex neurobiology ${ }^{28}$; however, three major clinical presentations are recognised. 
How to do it

Table 3 Some important 'chameleons' of dementia diagnosis

\begin{tabular}{|c|c|c|}
\hline Disease & Chameleons & Some useful features to identify the chameleon \\
\hline \multirow[t]{11}{*}{ Alzheimer's disease } & Mimics* & \\
\hline & Transient epileptic amnesia† & $\begin{array}{l}\text { Clinical seizures (not invariable), prominent fluctuation, 'vacational' amnesiał; abnormal (extended) } \\
\text { EEG, may have other features of limbic encephalitis, auto-antibodies / cancer }\end{array}$ \\
\hline & Obstructive sleep apnoeat & Daytime somnolence, non-refreshing sleep, heavy snoring (from partner); abnormal sleep study \\
\hline & Normal-pressure hydrocephalus ${ }^{\dagger}$ & May have gait apraxia, urinary dysfunction; MRI hydrocephalus and associated features \\
\hline & Vascular & MRI: strategic (eg, thalamic) infarct, other vascular patterns (including deep micro-haemorrhages) \\
\hline & $\begin{array}{l}\text { Traumatic brain injury/chronic traumatic } \\
\text { encephalopathy }\end{array}$ & History of significant (especially recurrent) head trauma \\
\hline & $\begin{array}{l}\text { Dementia with Lewy bodies frontotemporal } \\
\text { dementia and other neurodegenerative } \\
\text { disorders }\end{array}$ & $\begin{array}{l}\text { Vary according to underlying pathology; may have genetic mutation (frontotemporal dementia, } \\
\text { familial prion), some entities (eg, argyrophilic grain disease, limbic-predominant age-related TDP-43 } \\
\text { encephalopathy) currently only diagnosed post mortem }\end{array}$ \\
\hline & Variants & \\
\hline & $\begin{array}{l}\text { Posterior cortical atrophy } \\
\text { Logopenic aphasia } \\
\text { Behavioural variant frontotemporal-like } \\
\text { Corticobasal syndrome } \\
\text { Young onset (sporadic) }\end{array}$ & $\begin{array}{l}\text { Positive Alzheimer markers in CSF (raised total / phospho-tau, reduced beta-amyloid42 and beta- } \\
\text { amyloid42/40 ratio), cortical micro-haemorrhages associated with amyloid angiopathy }\end{array}$ \\
\hline & Rapid (may have beta-amyloid angiitis) & Positive Alzheimer CSF and MRI markers, cortical microhaemorrhages/siderosis on MRI \\
\hline & Familial & $\begin{array}{l}\text { Young, autosomal dominant family history (may be censored); may have spastic paraparesis/other } \\
\text { neurological signs (especially PS1 mutations), prominent neuropsychiatric features, white matter } \\
\text { change on MRI; PS1, PS2 or APP mutation (in addition to Alzheimer (SF markers) }\end{array}$ \\
\hline
\end{tabular}

\section{Dementia with Lewy Mimics}

bodies

Progressive supranuclear palsy and corticobasal syndrome

Variants

\section{Alzheimer-like}

Behavioural variant frontotemporal-like

Rapid

\begin{tabular}{|c|c|c|}
\hline \multirow{7}{*}{$\begin{array}{l}\text { Vascular cognitive } \\
\text { impairment }\end{array}$} & \multicolumn{2}{|l|}{ Mimics } \\
\hline & Infectious/inflammatory/autoimmune† & $\begin{array}{l}\text { Suggestive history, autoantibodies, blood/CSF serology (eg, human immunodeficiency virus and } \\
\text { syphilis) }\end{array}$ \\
\hline & Genetic arteriopathies & $\begin{array}{l}\text { Young, lack of vascular risk factors, suggestive family history; migraine, psychiatric features, MRI } \\
\text { involvement of anterior temporal lobe, NOTCH3 mutations with CADASIL }\end{array}$ \\
\hline & Primary leukodystrophies & $\begin{array}{l}\text { Young, lack of vascular risk factors, suggestive MRI (confluent, symmetric white matter change), } \\
\text { positive diagnostic tests }\end{array}$ \\
\hline & \multicolumn{2}{|l|}{ Variants } \\
\hline & Behavioural variant frontotemporal-like & MRI: significant vascular change, lack of suggestive atrophy profile \\
\hline & Prominent amnestic/focal 'cortical' deficits & MRI: strategic infarct (especially thalamus, parietal) \\
\hline \multirow{10}{*}{$\begin{array}{l}\text { Frontotemporal } \\
\text { dementia§ }\end{array}$} & \multicolumn{2}{|l|}{ Mimics } \\
\hline & $\begin{array}{l}\text { 'Frontotemporal dementia phenocopy' } \\
\text { (especially older men) }\end{array}$ & $\begin{array}{l}\text { Normal brain MRI/ fluorodeoxyglucose-PET; some frontotemporal dementia cases (especially C9orf72 } \\
\text { mutations) may be very slowly progressive-phenocopy cases often show better preserved insight } \\
\text { than is usual with frontotemporal dementia }\end{array}$ \\
\hline & Frontal variant of Alzheimer's disease & $\begin{array}{l}\text { Prominent associated episodic memory deficit, relatively prominent posterior atrophy on MRI, } \\
\text { Alzheimer biomarkers (CSF, amyloid PET) }\end{array}$ \\
\hline & Vascular & MRI: vascular features \\
\hline & Dementia with Lewy bodies & Visual hallucinations, REM sleep behaviour disorder \\
\hline & \multicolumn{2}{|l|}{ Variants } \\
\hline & Amnestic/Alzheimer-like & Negative Alzheimer biomarkers \\
\hline & Corticobasal syndrome & May have GRN mutation \\
\hline & Motor neurone disease & May have C9orf72 mutations \\
\hline & Very young onset/rapid & MRI: disproportionate caudate atrophy (FUS-opathy) \\
\hline \multicolumn{3}{|c|}{$\begin{array}{l}\text { Here, chameleons are either 'mimics'—a different disease that presents similarly to the typical syndrome, listed in the left-most column—or 'variants'—an alternative, atypical presentation } \\
\text { of the same disease process that causes the typical syndrome. } \\
\text { *Negative Alzheimer markers may be helpful but Alzheimer pathology frequently coexists with other entities (seizures, obstructive sleep apnoea more common in Alzheimer's disease). } \\
\text { tPotentially reversible process. } \\
\text { fNo recollection at all of salient events such as vacations (typically in Alzheimer's disease, there is some recollection of the episode, although degraded). } \\
\text { \$Presentation with behavioural variant here taken to be typical (clinical mimics of primary progressive aphasia syndromes are very uncommon). } \\
\text { APP, amyloid precursor protein; CADASIL, cerebral autosomal dominant arteriopathy with subcortical infarcts and leukoencephalopathy; C9orf72, mutation of chromosome } 9 \text { open reading } \\
\text { frame 72; CSF, cerebrospinal fluid; EEG, electroencephalogram; FUS, fused-in-sarcoma protein; GRN, progranulin gene; NOTCH3, neurogenic locus notch homolog protein } 3 \text { mutations; PET, } \\
\text { positron emission tomography; PS1, presenilin } 1 \text { gene mutation; PS2, presenilin } 2 \text { gene mutation. }\end{array}$} \\
\hline
\end{tabular}

Florid delirium, prominent fluctuations, early visual hallucinations, REM sleep behaviour disorder, emerging parkinsonism

Supranuclear gaze palsy, prominent asymmetric apraxia/axial rigidity; poor levodopa response

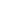




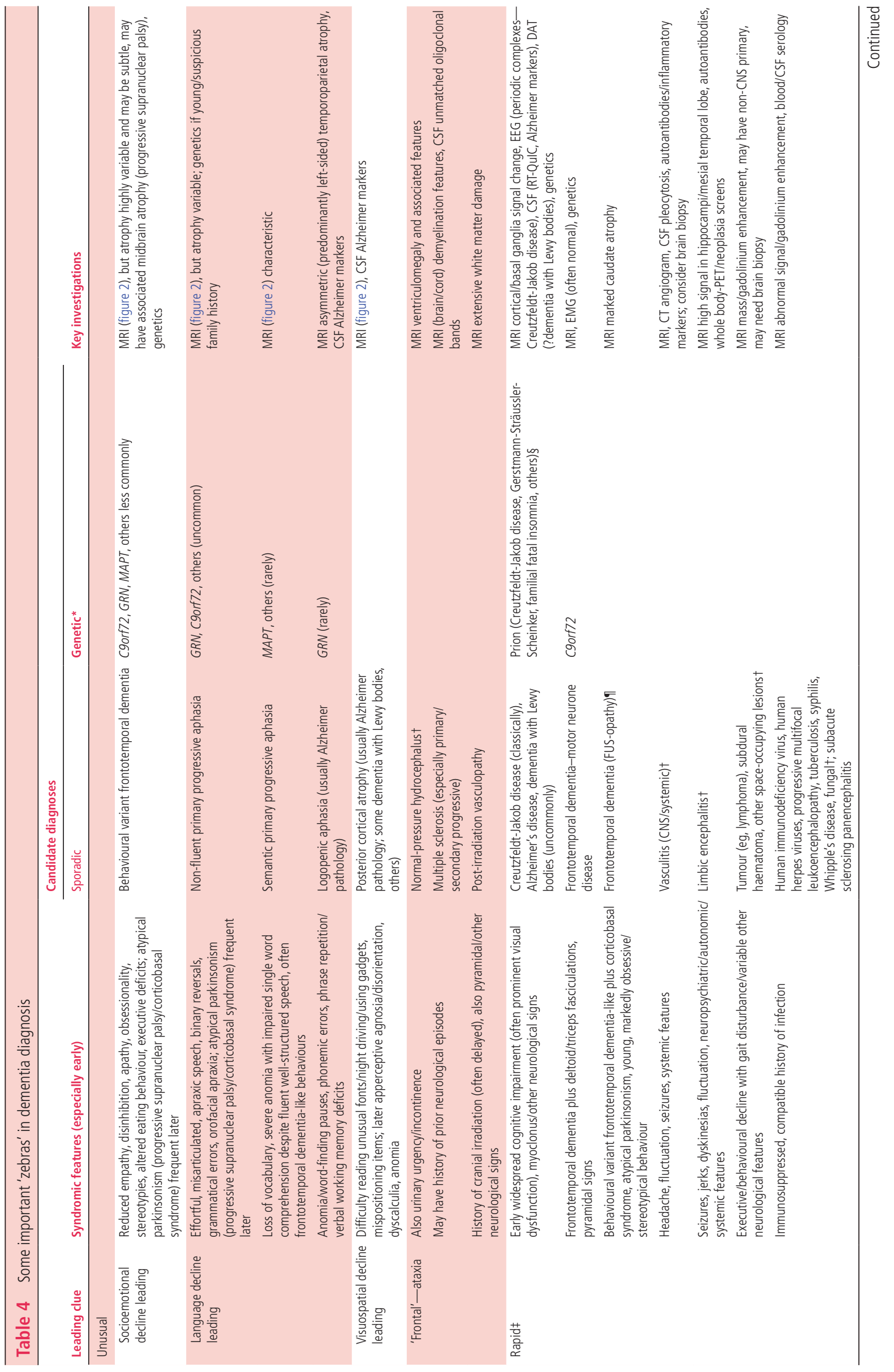

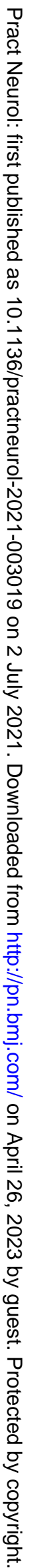




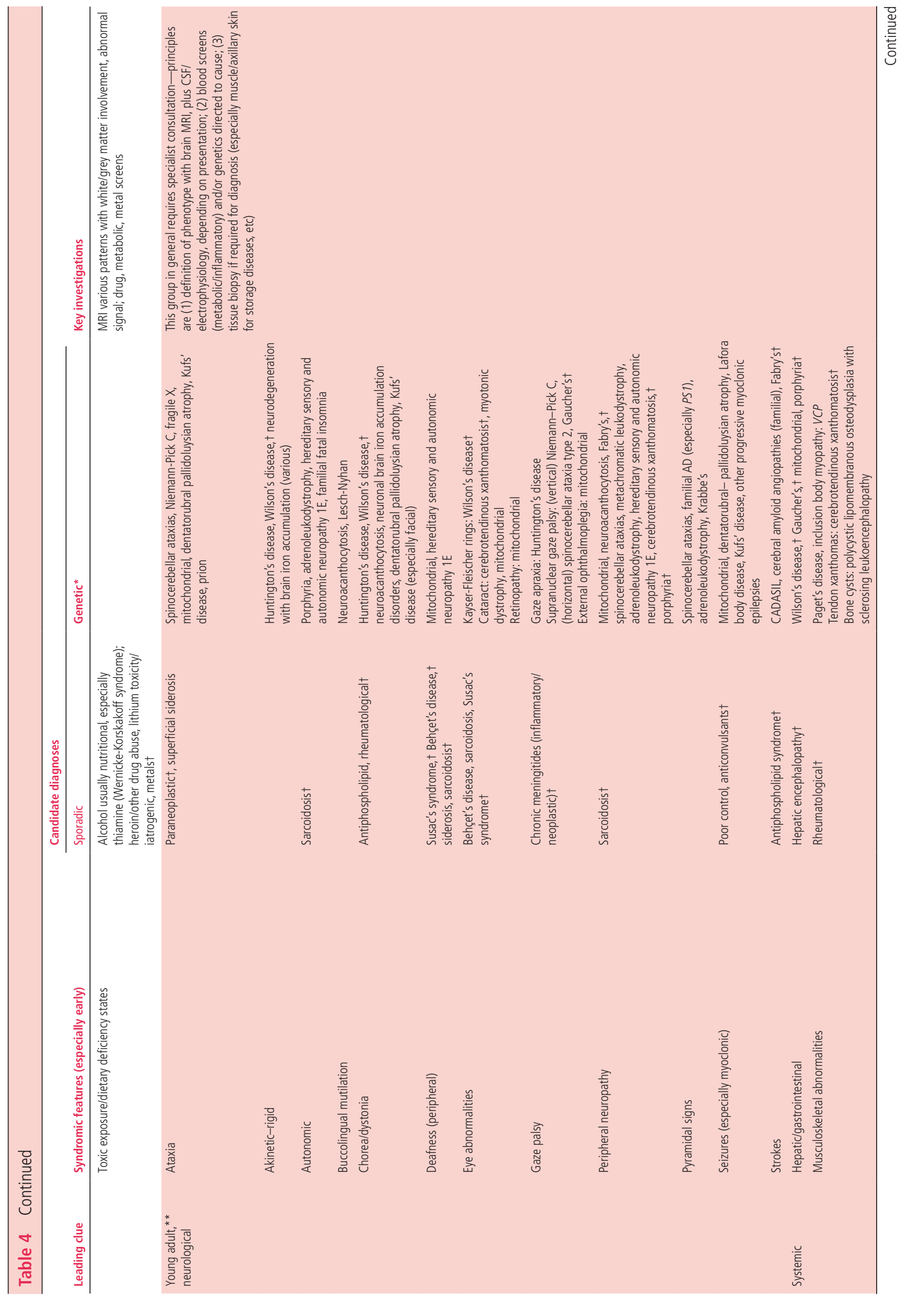




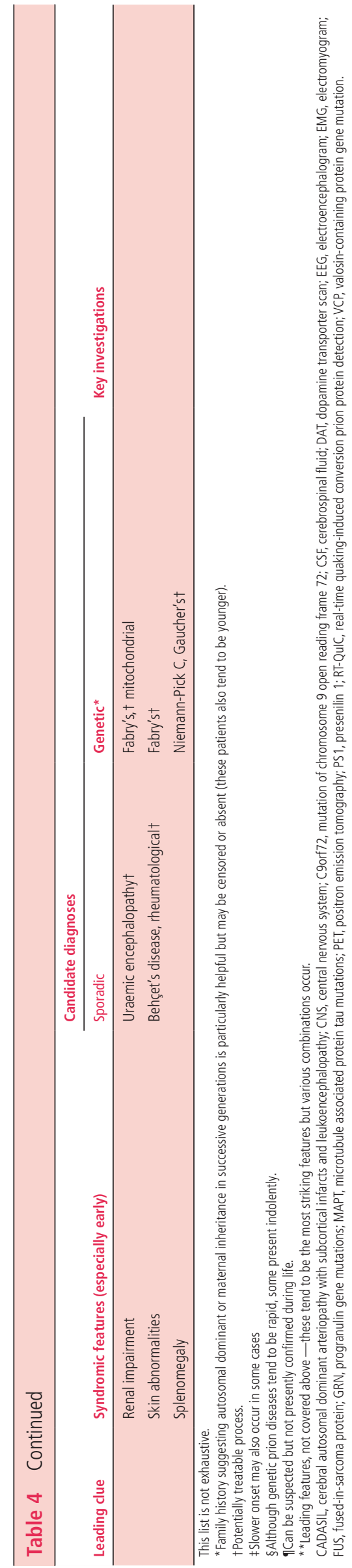

The behavioural variant of frontotemporal dementia presents with abnormalities of social and emotional awareness and reactivity. ${ }^{28} 29$ The patient generally lacks insight, but the family complains bitterly that they have 'changed', typically with loss of warmth and social skills (there may have been embarrassing faux pas), and frequently prominent apathy, rituals and/or impulsivity that may have resulted in loss of a job or ill-advised decisions. Gluttony and development of a pathological sweet tooth are characteristic, exemplifying a much broader repertoire of odd, inflexible and maladaptive behaviours with valuation of abstract or impersonal interests over other people. These features may be particularly striking in patients with selective right temporal lobe atrophy, ${ }^{30}$ who also frequently exhibit prosopagnosia. Behavioural variant frontotemporal dementia is challenging to diagnose, particularly early on, as there are few reliable biomarkers. Patients may do well on formal cognitive (including executive) tests. There are several highly pertinent clinical issues surrounding the diagnosis: it is genetically mediated in up to perhaps a third of cases (genetic testing for the three major causative, autosomal dominant mutations should be considered in all younger patients) and vigilant neurological follow-up is indicated, both to detect the emergence of major associations (atypical parkinsonism or motor neurone disease) and to identify patients who fail to manifest abnormalities on brain MRI or metabolic (fluorodeoxyglucose - positron emission tomography (FDGPET) or single-photon emission computed tomography (SPECT)) imaging. The nosological status of these latter 'phenocopy' cases is still unclear.

Among language-led dementia syndromes (the primary progressive aphasias), the non-fluent/agrammatic variant is the most immediately clinically striking. These patients characteristically have effortful, unmelodious, misarticulated 'apraxic' speech and their utterances may be terse and agrammatic ('telegraphic'). Early on, there may be particular difficulty with public speaking, reversing of 'yes' and 'no' or re-emergence of a childhood stutter. Initially, naming and comprehension are largely intact and written expression is usually more fluent than speech. ${ }^{2526}$ As the syndrome evolves, impairments of orofacial praxis (affecting volitional movements such as whistling) and dysphagia often supervene, frequently with emergence of an extrapyramidal syndrome in the corticobasal-progressive supranuclear palsy spectrum.

In contrast, the semantic variant of primary progressive aphasia presents with increasingly circumlocutory and vacant speech that is well constructed and fluent (even garrulous). These patients characteristically have asked family members the meanings of words ('What's a tornado?') and often compile personal 'dictionaries'. They have early, profound anomia, underpinned by impaired single-word comprehension and vocabulary loss affecting all language channels, often extending to a tendency to sound irregular words (such as 'sew') as they are printed ('surface dyslexiaa ${ }^{25}{ }^{26}$ ). The true 


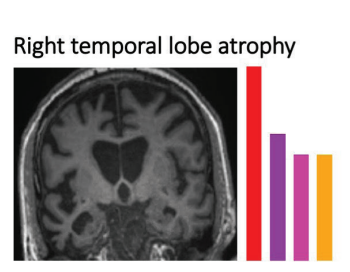

Alzheimer's Disease

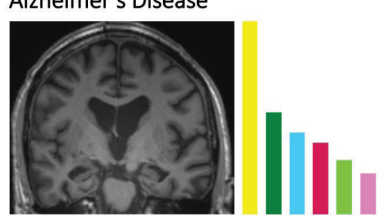

Posterior cortical atrophy

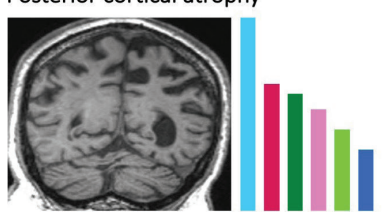

Behavioural variant

frontotemporal dementia

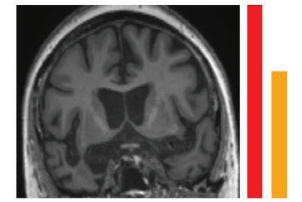

Nonfluent variant primary progressive aphasia

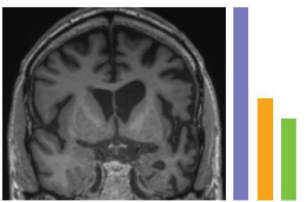

Semantic variant primary progressive aphasia

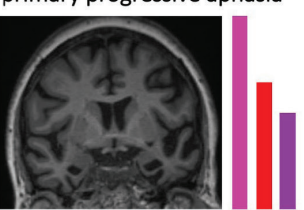

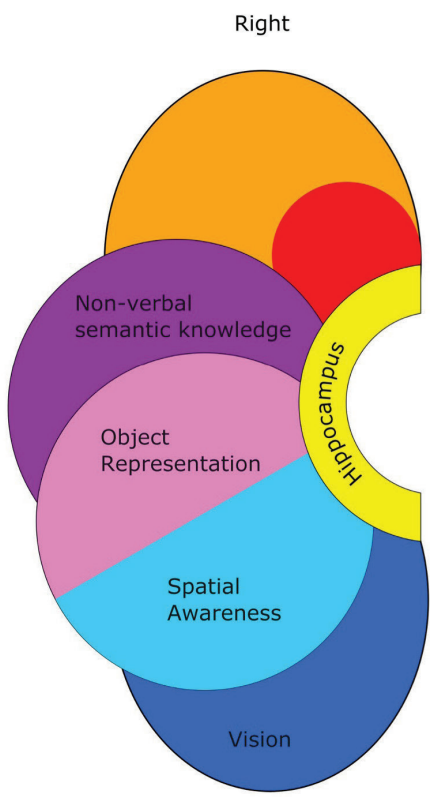

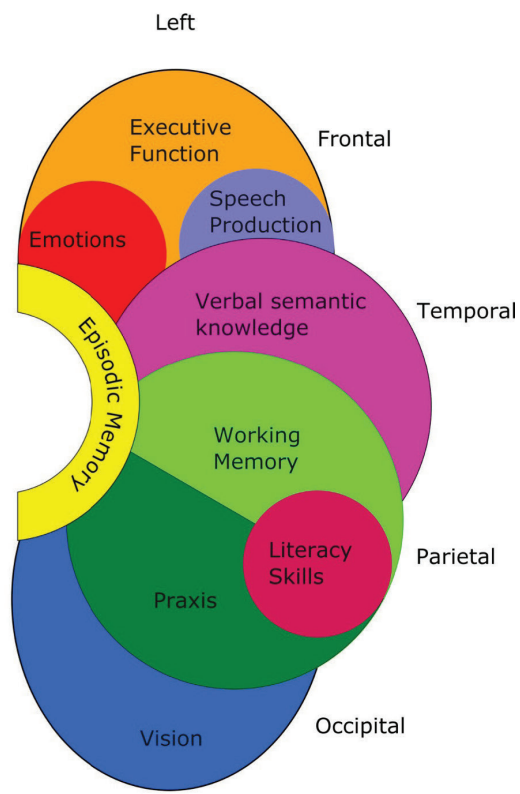

Figure 2 Cognitive and neuroanatomical profiles of some major dementia syndromes. The cartoon brain (right) shows cognitive functions predominantly mediated by different cerebral regions in each cerebral hemisphere. The T1-weighted coronal MRI sections (left) show characteristic patterns of regional brain atrophy in representative neurodegenerative disorders (typical Alzheimer's disease-disproportionate, bilateral hippocampal atrophy; behavioural variant frontotemporal dementia_predominant bilateral but asymmetric, frontal and anterior temporal lobe atrophy; non-fluent/agrammatic variant primary progressive aphasia—predominantly leftsided, anterior peri-Sylvian cortical atrophy; posterior cortical atrophy - predominant biparietal atrophy; semantic variant primary progressive aphasia—selective, predominantly left-sided anteromesial and inferior temporal lobe atrophy; right temporal lobe atrophy—selective, predominantly right-sided anterior temporal lobe atrophy). In each case, the dementia syndrome reflects a profile of brain network breakdown (see also table 1); this correspondence is indicated by the coloured histograms alongside each scan, which code the cognitive domains pre-eminently affected in each syndrome. The histogram colours follow the same convention as the brain cartoon; the heights of the histogram bars are arbitrary but indicate the relative clinical prominence of deficits across cognitive domains that are typically seen in a particular syndrome. The left hemisphere is projected on the right (following standard clinical convention) throughout.

nature of this syndrome is captured in its older designation, 'semantic dementia': this is the paradigmatic disorder of the semantic memory system that mediates knowledge about words, objects and concepts. As it evolves, non-verbal semantic knowledge about visual and other sensory objects and about the emotional and social signals of other people also disintegrates. Patients generally develop a behavioural syndrome similar to behavioural variant frontotemporal dementia. In our experience, there is invariably focal, asymmetric,

\section{Key points}

- Dementia is a syndrome of progressive decline in cognitive function and/or behaviour that impacts upon daily life functioning and has multiple potential causes.

- Timely diagnosis is desirable and achievable with a systematic approach to cognitive assessment.

- The major dementias target particular brain networks and accordingly have distinct phenotypes.

- The diagnosis rests primarily on clinical assessment, with neuropsychological, neuroimaging and biomarker support where appropriate. usually predominantly left-sided anterior temporal lobe atrophy on brain MRI at presentation (figure 2); if this is absent, we hesitate to invoke the diagnosis.

\section{Other 'zebras'}

These are many and diverse (table 4): clues to their presence include younger age of onset, a family history of younger onset dementia (often labelled as Alzheimer's disease or psychiatric illness), prominent extracognitive neurological or systemic features or a rapid course. The last group includes catastrophic illnesses such as prion disease but also several reversible processes that demand careful exclusion (table 4). Diagnosis of the many rare diseases that cause dementia in younger adults due to metabolic, inflammatory, storage and other inherited disorders generally depends on clinical features or markers beyond cognition ${ }^{31}{ }^{32}$ : these disorders tend to produce a fairly nondescript 'frontosubcortical' cognitive syndrome led by executive and neuropsychiatric dysfunction.

\section{NEXT STEPS AFTER SUSPECTING DEMENTIA}

If available, more detailed cognitive testing with a neuropsychologist is often a valuable extension to the bedside assessment to: quantify suspected deficits 
in relation to age-appropriate norms and premorbid attainment; detect deficits in domains (such as executive function) that are challenging to assess at the bedside; and compare performance over serial assessments, which may be diagnostic in cases of clinical doubt.

Any patient with suspected dementia should have brain imaging (ideally MRI)—occasionally this will show a surgically remediable process but more generally it defines the profile of atrophy in neurodegenerative diseases (figure 2) and detects signal alterations such as those associated with cerebrovascular disease, leukodystrophies and prion disease. Serial imaging of change over a year or more can be informative if the first scan is normal. Conversely, frontal or parietal 'atrophy' is quite commonly overinterpreted on MRI. Brain FDG-PET or SPECT is sometimes useful to demonstrate regional cerebral hypometabolism where Alzheimer's disease or a frontotemporal dementia is suspected but MRI is inconclusive.

Although basic haematological and metabolic screens are worthwhile to detect potentially reversible factors that may contribute to cognitive decline, these are rarely the primary culprit. Diagnostic markers of dementia are currently largely derived from CSF analysis, which should be considered in anyone with younger onset dementia (arbitrarily, before the age of 65 years) or rapid evolution, when it is likely to have the most useful predictive value (see tables 3 and 4)relevant CSF constituents include cells and oligoclonal bands (pointers to brain inflammation), neurofilament light chain (a non-specific indicator of the presence and severity of neuronal damage) and more specific protein profiles of Alzheimer pathology (raised total and phospho-tau, elevated tau:beta-amyloid42 or beta-amyloid40:amyloid42 ratio).

Diagnostic testing for causative genetic mutations should be considered in younger patients where there is a compatible phenotype and in particular a suggestive (autosomal dominant) family history, but only after appropriately informed counselling in the clinic, particularly with respect to the implications for other family members. Other more specialised investigations may be appropriate in certain clinical contexts (see table 4).

Local services should be engaged for support early and people with atypical forms of Alzheimer's disease or nonAlzheimer dementias can be directed to Rare Dementia Support (https://www.raredementiasupport.org/).

\section{CONCLUSIONS}

Early and accurate diagnosis of dementia is desirable and achievable, but it must first be suspected. As always in neurology, pattern recognition is key. The first challenge is to determine whether dementia is likely and then, based on a functionally oriented history and systematic examination, to determine the profile of cerebral involvement and thus the candidate underlying pathology. Despite a growing array of ancillary

\section{Further reading}

McWhirter L, Ritchie C, Stone J, et al. Functional cognitive disorders: a systematic review. Lancet Psychiatry 2020;7:191-207.0xford Textbook of Cognitive Neurology and Dementia. Husain M, Schott JM, editors. Oxford University Press; 2016.

- Crutch SJ, Lehmann M, Schott JM, et al. Posterior cortical atrophy. Lancet Neurol 2012;11:170-8.

- Sivasathiaseelan $\mathrm{H}$, Marshall CR, Agustus JL, et al. Frontotemporal dementia: a clinical review. Semin Neurol 2019;39:251-63.

tools, clinical judgement is likely to remain essential and indeed, to assume even greater importance as effective treatments become available.

Twitter Chris J D Hardy @cjdhardy, Charles R Marshall @ charl_marshall, Jonathan D Rohrer@ftdtalk, Jonathan M Schott@jmschott and Rimona S Weil@rimonaweil

Acknowledgements The Dementia Research Centre is supported by Alzheimer's Research UK, Brain Research UK, and the Wolfson Foundation. This work was supported by the Alzheimer's Society, Alzheimer's Research UK and the National Institute for Health Research University College London Hospitals Biomedical Research Centre.

Contributors JCSJ and JDW conceived of and drafted the main manuscript. All authors contributed significantly to the content of the manuscript and reviewed the drafts and provided feedback.

Funding JCSJ is supported by an Association of British Neurologists Clinical Research Training Fellowship, funded by Guarantors of Brain. CJDH is supported by a RNIDDunhill Medical Trust Pauline Ashley Fellowship (PA23). SJC receives support from the ESRC/NIHR Dementia Research Initiative (ES/S010467/1). CRM is supported by a grant from Bart's Charity. RSW is supported by a Wellcome Clinical Research Career Development Fellowship (201567/Z/16/Z). $\mathrm{LMcW}$ receives philanthropic funding from Baillie Gifford. JDW receives grant support from Alzheimer's Research UK, the Alzheimer's Society and the National Brain Appeal (Frontotemporal Dementia Research Studentship in Memory of David Blechner).

Competing interests None declared.

Patient consent for publication Not required.

Provenance and peer review Commissioned. Externally peer reviewed by Anthony Bayer, Cardiff, UK.

\section{ORCID iDs}

Jeremy C S Johnson http://orcid.org/0000-0002-4265-7997 Rimona S Weil http://orcid.org/0000-0002-5092-6325

\section{REFERENCES}

1 Livingston G, Sommerlad A, Orgeta V, et al. Dementia prevention, intervention, and care. Lancet 2017;390:2673-734.

2 Dubois B, Padovani A, Scheltens P, et al. Timely Diagnosis for Alzheimer's Disease: A Literature Review on Benefits and Challenges. JAD 2015;49:617-31. 
3 Warren JD, Rohrer JD, Schott JM, et al. Molecular nexopathies: a new paradigm of neurodegenerative disease. Trends Neurosci 2013;36:561-9.

4 McWhirter L, Ritchie C, Stone J, et al. Functional cognitive disorders: a systematic review. Lancet Psychiatry 2020;7:191-207.

5 Association AP, Force APAD-5 T, editors. Depressive Disorders. In: Diagnostic and statistical manual of mental disorders. Arlington, VA: American Psychiatric Association, 2013.

6 Johansson M, Stomrud E, Lindberg O, et al. Apathy and anxiety are early markers of Alzheimer's disease. Neurobiol Aging 2020;85:74-82. doi:10.1016/j. neurobiolaging.2019.10.008

7 Segers K, Benoit F, Meyts J-M, et al. Anxiety symptoms are quantitatively and qualitatively different in dementia with Lewy bodies than in Alzheimer's disease in the years preceding clinical diagnosis. Psychogeriatrics 2020;20:242-6. doi:10.1111/psyg. 12490

8 Johnson JCS, Marshall CR, Weil RS, et al. Hearing and dementia: from ears to brain. Brain 2021;144:391-401. doi:10.1093/brain/awaa429

9 Fukui T, Yamazaki T, Kinno R. Can the 'head-turning sign' be a clinical marker of Alzheimer's disease? Dement Geriatr Cogn Dis Extra 2011;1:310-7. doi:10.1159/000332605

10 McKeith IG, Boeve BF, Dickson DW, et al. Diagnosis and management of dementia with Lewy bodies. Neurology 2017;89:88-100. doi:10.1212/WNL.0000000000004058

11 Matar E, Shine JM, Halliday GM, et al. Cognitive fluctuations in Lewy body dementia: towards a pathophysiological framework. Brain 2020;143:31-46. doi:10.1093/brain/awz311

12 McKeith IG, Ferman TJ, Thomas AJ, et al. Research criteria for the diagnosis of prodromal dementia with Lewy bodies. Neurology 2020;94:743-55.

13 Fujishiro H, Iseki E, Nakamura S, et al. Dementia with Lewy bodies: early diagnostic challenges. Psychogeriatrics 2013;13:128-38. doi:10.1111/psyg.12005

14 van der Flier WM, Skoog I, Schneider JA, et al. Vascular cognitive impairment. Nat Rev Dis Primers 2018;4:18003. doi:10.1038/nrdp.2018.3

15 Dichgans M, Leys D. Vascular cognitive impairment. Circ Res 2017;120:573-91.

16 Warren JD, Fletcher PD, Golden HL. The paradox of syndromic diversity in Alzheimer disease. Nat Rev Neurol 2012;8:451-64. doi:10.1038/nrneurol.2012.135

17 Crutch SJ, Lehmann M, Schott JM, et al. Posterior cortical atrophy. Lancet Neurol 2012;11:170-8.

18 Schott JM, Warren JD. Alzheimer's disease: mimics and chameleons. Pract Neurol 2012;12:358-66. doi:10.1136/ practneurol-2012-000315

19 Atherton KE, Filippini N, Zeman AZJ, et al. Encodingrelated brain activity and accelerated forgetting in transient epileptic amnesia. Cortex 2019;110:127-40. doi:10.1016/j. cortex.2018.04.015

20 Zeman A, Butler C. Transient epileptic amnesia. Curr Opin Neurol 2010;23:610-6. doi:10.1097/ WCO.0b013e32834027db

21 Olaithe M, Bucks RS, Hillman DR, et al. Cognitive deficits in obstructive sleep apnea: insights from a meta-review and comparison with deficits observed in COPD, insomnia, and sleep deprivation. Sleep Med Rev 2018;38:39-49. doi:10.1016/j.smrv.2017.03.005

22 Bubu OM, Pirraglia E, Andrade AG, et al. Obstructive sleep apnea and longitudinal Alzheimer's disease biomarker changes. Sleep 2019;42. doi:10.1093/sleep/zsz048. [Epub ahead of print: 11 Jun 2019].

23 Müller-Schmitz K, Krasavina-Loka N, Yardimci T, et al. Normal pressure hydrocephalus associated with Alzheimer's disease. Ann Neurol 2020;88:703-11.

24 Oliveira LM, Nitrini R, Román GC. Normal-Pressure hydrocephalus: a critical review. Dement Neuropsychol 2019;13:133-43.

25 Marshall CR, Hardy CJD, Volkmer A, et al. Primary progressive aphasia: a clinical approach. J Neurol 2018;265:1474-90. doi:10.1007/s00415-018-8762-6

26 Gorno-Tempini ML, Hillis AE, Weintraub S, et al. Classification of primary progressive aphasia and its variants. Neurology 2011;76:1006-14.

27 Ossenkoppele R, Pijnenburg YAL, Perry DC, et al. The behavioural/dysexecutive variant of Alzheimer's disease: clinical, neuroimaging and pathological features. Brain 2015;138:2732-49.

28 Sivasathiaseelan H, Marshall CR, Agustus JL, et al. Frontotemporal dementia: a clinical review. Semin Neurol 2019;39:251-63.

29 Rascovsky K, Hodges JR, Knopman D, et al. Sensitivity of revised diagnostic criteria for the behavioural variant of frontotemporal dementia. Brain 2011;134:2456-77.

30 Ulugut Erkoyun H, Groot C, Heilbron R, et al. A clinicalradiological framework of the right temporal variant of frontotemporal dementia. Brain 2020;143:2831-43.

31 Lynch DS, Wade C, Paiva ARBde, et al. Practical approach to the diagnosis of adult-onset leukodystrophies: an updated guide in the genomic era. J Neurol Neurosurg Psychiatry 2019;90:543-54. doi:10.1136/jnnp-2018319481

32 Rossor MN, Fox NC, Mummery CJ, et al. The diagnosis of young-onset dementia. Lancet Neurol 2010;9:793-806.

33 Mitchell AJ. A meta-analysis of the accuracy of the MiniMental state examination in the detection of dementia and mild cognitive impairment. J Psychiatr Res 2009;43:411-31. 